\title{
EXPERIMENTAL RESEARCH FOR PREPARING THE PHYSICAL CHARACTERISTICS OF STUDENTS
}

\author{
L. Lapadatov*, G. Dyakova, N. Gocheva, M. Ivanova, T. Andreev \\ Department of Physical Education and Sport, Trakia University, Stara Zagora, Bulgaria
}

\begin{abstract}
Research with students was conducted at the Trakia University- Stara Zagora. Sixty-six students (women) from the first and second year of their study from all specialties in the Faculty of Veterinary Medicine, Faculty of Agriculture and Faculty of Economics participated in the research. They were randomly divided into two groups: an experimental group (36 students) and a control group (30 students). The purpose of the research was to discover the impact of the experimental methods for preparing the physical characteristics of the student. For the purpose of the research were applied Theoretical Analysis, Sports and Pedagogical Tests, Pedagogical Experiment, Variation Analysis, Graphic Analysis and Comparative Analysis. A test battery including 5 tests for physical characteristics was prepared. From the analysis of the results can be seen that the conducted research was successful and the used methods were effective.
\end{abstract}

Key words: Higher School, Experiment, Physical Characteristics

\section{INTRODUCTION}

The decreased physical activity and increased mental load and stress are typical for the students during their course of study at the universities. Different physical exercises and sports can help the students to overcome fatigue and to recover themselves faster and more efficiently.

Krum Rachev points out that the formative effect of traditional physical education at our schools is too weak - only $15 \%$ (1).

In the recent years, in order to stimulate sports and physical activity and improve the physical preparation of the students, the sports professionals paid more attention to update the content of the familiar sports disciplines and to introduce new ones (2).

Many scientists believe that the performance of mobility tasks basically depends on the functional condition of the person. Muscle strength and endurance are an essential part

*Correspondence to: Lyuben Lapadatov, Trakia

University, Department of Physical Education and Sport, Stara Zagora, Bulgaria, e-mail

luben82@mail.bg,lyuben.lapadatov@trakiauni.bg of the personal physical capacity. Strength as one of the physical characteristics of the person is the basis of mobility activity. Thanks to the strength and its development, we are able to perform daily tasks and to react to an extreme situation for the body. It is the basis for the sports technique and also helps for improving the sports achievements (3-7).

The research was conducted with students from the Trakia University in Stara Zagora. Sixty six students from the first and secondyear (women) of their study, from the Faculty of Veterinary Medicine, the Faculty of Agriculture and the Faculty of Economics participated in the research. They were randomly divided into an experimental group (36 students) and a control group (30 students).

The Purpose of the research was to find out the impact of the experimental methods for the preparing of physical characteristics.

Tasks:

1. Study of the literature;

2. Preparing the test battery; 
3. Creating and experimenting fitness program with Swiss balls;

4. Analysis of the results;

For the purpose of the research, the following methods were used:

1. Theoretical analysis;

2. Sport-pedagogical tests;

3. Pedagogical experiment;

4. Variation analysis;

5. Graphic analysis;

6. Comparative analysis;

The created test battery includes 5 tests:

1. Long jump from a spot with both legs;

2. Push-ups to failure;

3. Hang-up to failure;

4. Throwing a medicine ball $(3 \mathrm{~kg})$ with both hands overhead onward;

5. Throwing a medicine ball $(3 \mathrm{~kg})$ with both hands backward.

\section{RESULTS}

The results from the test "Long jump from a spot" of the two groups during the first research vary between 100 and $200 \mathrm{~cm}$. The rates of variation are about $10 \%$, which
LAPADATOV L., et al.

shows a similar rate of variability of the results.

The results from the experimental test "Long jump from a spot" can be seen in Figure 1. The students from EG showed an average rate of $143.65 \mathrm{~cm}$ at the entrance tests, and at the outgoing ones - an average rate of 153.87 $\mathrm{cm}$. The students from CG showed the following results during the first research - an average rate of $153.87 \mathrm{~cm}$, during the second research $-152.67 \mathrm{~cm}$. The increment of the experimental group is $10.22 \mathrm{~cm}$. It is statistically significant $(\alpha=0.000)$ and large from a practical point of view (Cohen's $d=$ 1.87). The control group reduced the results by $1.2 \mathrm{~cm}$.

The difference between the rates of the two groups is $11.42 \mathrm{~cm}$, which shows a statistically significant effect of the conducted fitness model. The Eta2 rate shows that $69 \%$ of the differences in the increment rates of the speed and power characteristics of the lower limbs during the research period are due to the applied by us training methods and means.

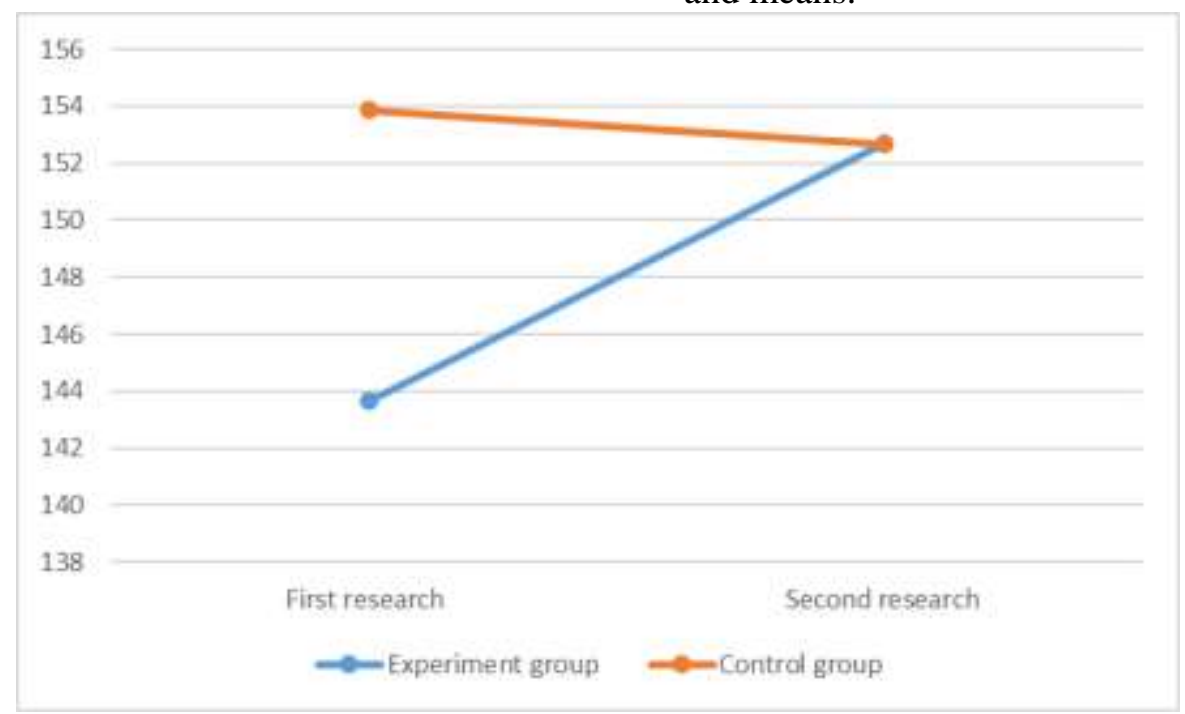

Figure 1. Long jump from a spot

The results from the test "Push-ups to failure" of the two groups during the first research vary between 2 and 46 pcs. The rate of variation in the results is about $38 \%$, which is a high rate of variability.

The results from the test "Push ups to failure" can be seen on Figure 2. The students from EG showed an average rate of 14.15 pcs. at the entrance tests, and an average rate of 20 pcs. at the outgoing tests. The students from CG showed the following results during the first research - an average rate of $17.73 \mathrm{pcs}$, during the second research 16.43 pcs. The increment of the experimental group is 5.85 pcs. It is statistically significant $(\alpha=0.000)$ and significant from a practical point of view (Cohen's $d=0.68)$. The control group reduced the results by 1,3 pcs.

The difference between the increments of the two groups is 7.15 pcs., which shows a statistically significant effect of the conducted fitness model. The Eta2 rate shows that $69 \%$ of the differences in the increment rates of the strength capacity of the arm muscles during the research period are due to the applied by us training methods and means. 


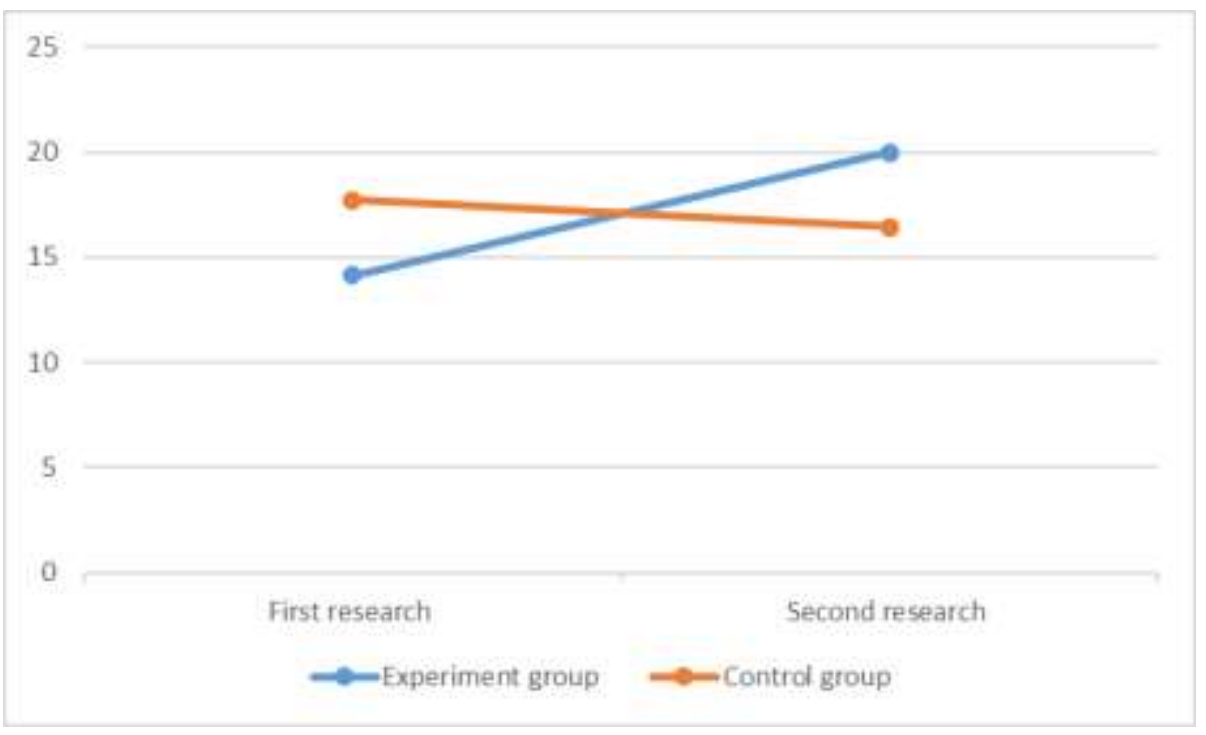

Figure 2. Push-ups to failure

The results from the test "Hang up to failure" of the two groups in the first research varied between 1 and $78 \mathrm{~s}$. The rate of variation is about $54 \%$, which shows a high rate of variability in the results.

The results from the experimental test "Pushups to failure" can be seen on Figure 3. The students from the EG showed an average rate of $29.18 \mathrm{~s}$ at the entrance tests, and an average rate of $34.79 \mathrm{~s}$ at the outgoing tests. The students from the CG have had the following results during the first research an average rate of $34.97 \mathrm{~s}$, in the second research - $32.3 \mathrm{~s}$. The increment of the experimental group is $5.61 \mathrm{~s}$. It is statistically significant $(\alpha=0.000)$ and significant from a practical point of view (Cohen's $d=0.72$ ). The control group reduced the results by 2.67 s.

The rate of variability between the increments of the two groups is $8.28 \mathrm{~s}$, which represents a statistically significant effect of the conducted fitness model. The Eta2 rate shows that $39 \%$ of the differences in the increment rates of the strength capacity of the arm muscles during the research period are due to the applied by us training methods and means.

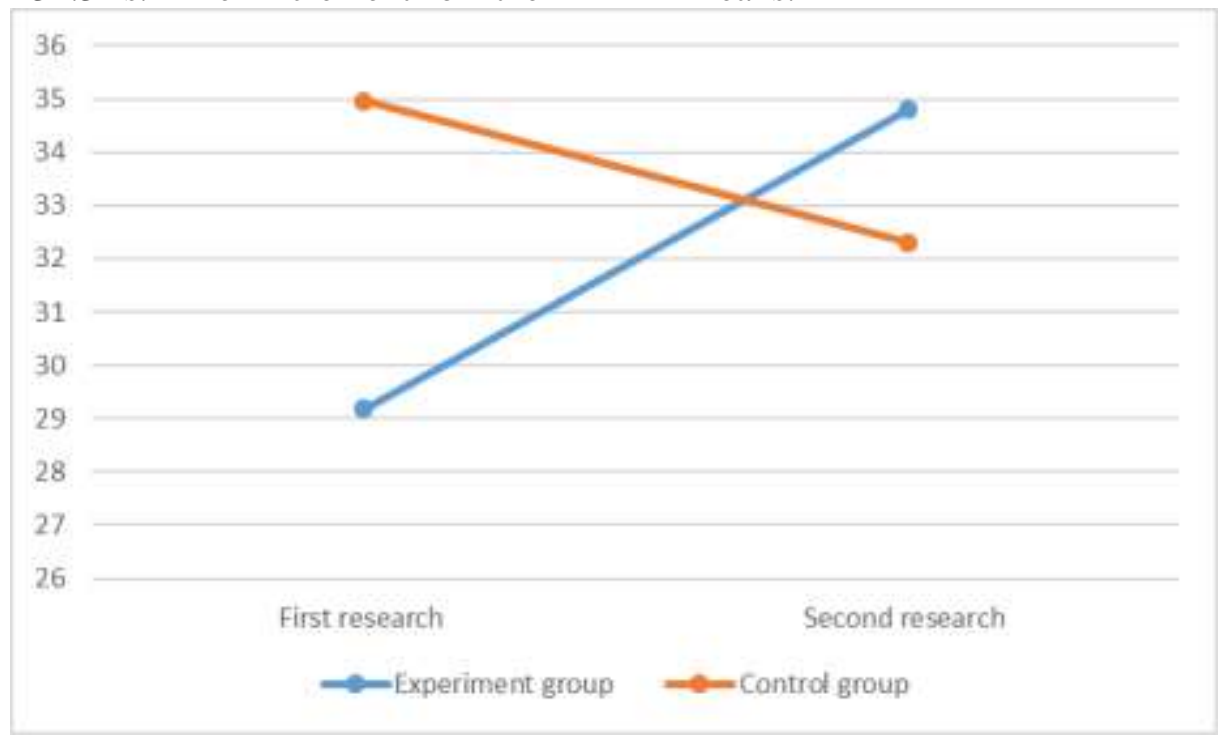

Figure 3. Hang-up to failure

The results from the test "Throwing a medicine ball onward " of the two groups during the first research varied between 210 and $660 \mathrm{~cm}$. The rate of variation is about
$12 \%$, which is a similar rate of variation of the results.

The experimental test "Throwing a medicine ball forward" results can be seen on Figure 4. The students from EG have had an average 
rate of $405.59 \mathrm{~cm}$ at the entrance tests, and at the outgoing tests - an average rate of 449.71 $\mathrm{cm}$. The students from $\mathrm{CG}$ have had the following results during the first research - an average rate of $474.33 \mathrm{~cm}$, and during the second research- $478.5 \mathrm{~cm}$. The increment of the experimental group is $44.12 \mathrm{~cm}$. It is statistically significant $(\alpha=0.000)$ and large from a practical point of view (Cohen's $d=$ 1.28). The Control Group increased the results by $4.17 \mathrm{~cm}$.
LAPADATOV L., et al.

The variation between the increments of the two groups is $39.95 \mathrm{~cm}$, which shows a statistically significant effect of the conducted fitness model. The Eta2 rate shows that $75 \%$ of the variation in the increment rates of the speed and power characteristics of the upper limbs during the research period is due to the applied by us training methods and means.

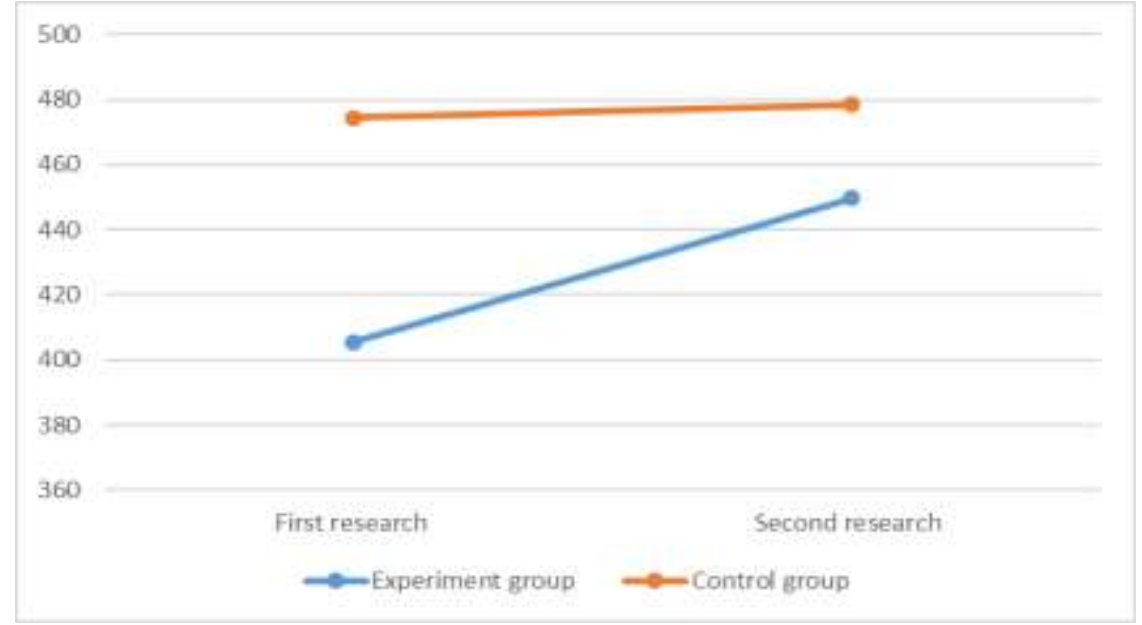

Figure 4. Throwing a medicine ball onward

The results from the test "Throwing a medicine ball backward" of the two groups during the first research varied between 310 and $780 \mathrm{~cm}$. The rate of variation is about $17.63 \%$, which is a similar rate of the variability of the results.

The results from the experimental test "Throwing a medicine ball backward" can be seen on Figure 5. The students from the EG have had an average rate of $477.65 \mathrm{~cm}$ at the entrance tests, and an average rate of 507.94 $\mathrm{cm}$ at the outgoing tests. The students from CG showed the following results during the first research - average rate of $522.67 \mathrm{~cm}$ and during the second research $515.2 \mathrm{~cm}$. The increment rate of the experimental group is $30.29 \mathrm{~cm}$. It is statistically significant $(\alpha=$ 0.000 ) and large from a practical point of view (Cohen's $d=0.86$ ). The Control Group reduced the results by $7.47 \mathrm{~cm}$.

The variability between the increment rates of the two groups is $37.76 \mathrm{~cm}$, which proves the statistically significant effect of the applied fitness model. The Eta2 rate shows that $43 \%$ of the variation in the increment rates of the speed and strength characteristics of the muscles of the arms and back during the experimental period is due to the applied by us training methods and means.

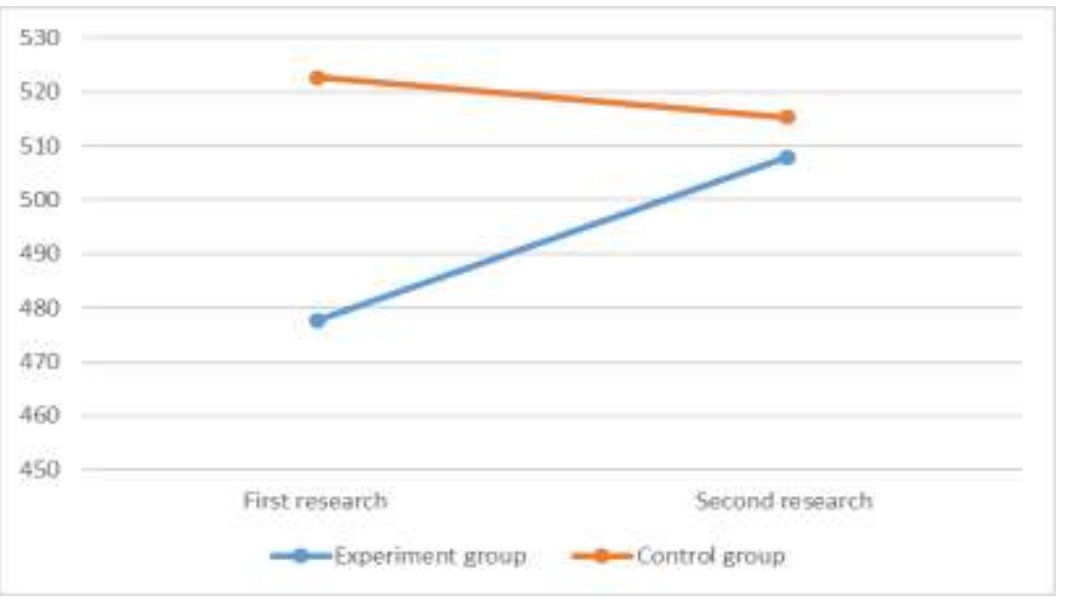

Figure 5. Throwing a medicine ball backward 


\section{CONCLUSIONS:}

1. The groups have had a similar and high level of variability in the results.

2. As a result of the applied fitness model, there is a statistically significant positive change in the observed indicators of the experimental group.

3. The results of the control group have deteriorated or have insignificant improvements.

\section{REFERENCES}

1. Rachev, Kr. Problems of the physical education in connection with the educational reform at the schools in the Republic of Bulgaria, "Sports and Science", №9, 1994.

2. Ivanova,M., Petkov, $P$ "Innovative Methods For Developing Physical Strengths And Endurance In Students", "Trakia Journal of Sciences", Vol. 17, Suppl. 1, pp 821-825, 2019, ISSN 1313-3551

3. Petkov, P., Correlation between Muscle Strength and Endurance when Using Specialized Fitness Training for Students, "Trakia Journal of Sciences", Vol. 17,

\section{LAPADATOV L., et al.}

Suppl. 1, pp 807-812, 2019, ISSN 13133551 ;

4. Dyakova G., Petkov P., Dobrev J., Andreev T., Gocheva N., Andreev T., Ivanova, M., Evaluation Comparative Analysis for the Prepared Health Profile of Students, NSA "Sports and Science", 3/2015, ISSN 13103393, pp.97-103

5. Peltekova I., Petkov P., Rating the level of physical characteristics of female groups of students in the physical education and sports classes at the Trakia University, "Sport and Science", Sofia, 2/2017, ISSN 1310-3393, p. 161- 169;

6. Dyakova, G., Petkov, P. Use of circular activities by students,. "Kinesiology 2012", University of Veliko Tarnovo, ISSN 1313-244X, p.77-82;

7. Petkov, P., Specialized fitness training by students, Dissertation for awarding the educational and scientific degree "DOCTOR", Supervisor: Assoc. Prof. Iren Peltekova, Doctor; Scientific consultant: Prof. Galina Dyakova, Doctor; Scientific specialty "Theory and methods of the physical education and sport training "University of Veliko Tarnovo". 